See discussions, stats, and author profiles for this publication at: https://www.researchgate.net/publication/333673267

\title{
Las plantas de Francisco José de Caldas y su contribución a los herbarios y
} escritos de la Flora de Bogotá.

Chapter · March 2019

DOI: 10.12804/th9789587841923.

\section{CITATIONS}

0

1 author:

José Luis Fernández-Alonso

Spanish National Research Council

210 PUBLICATIONS 897 CITATIONS

SEE PROFILE

Some of the authors of this publication are also working on these related projects:

READS

1,496

Project Los usos tradicionales de las plantas no maderables de Santa María, Boyacá (Andes Colombianos) View project

Project Taxonomic diversity and trophic relationships of leaf-mining Nepticuloidea \& Tischerioidea View project 


\title{
Las plantas de Francisco José de Caldas y su contribución a los herbarios y escritos de la Flora de Bogotá
}

\author{
José Luis Fernández-Alonso*
}

\begin{abstract}
Resumen
Por sugerencia de José Celestino Mutis, Francisco José de Caldas emprendió a partir de 1801 un concienzudo trabajo botánico en Ecuador, que se prolongaría hasta 1805. Los resultados fueron muy fructíferos, como consta en su relación de viajes y en sus manuscritos sobre las especies de quina de Ecuador y sobre otras plantas, que solo en parte logró publicar. El aporte al herbario de la Expedición Botánica en Bogotá de cerca de 6000 pliegos disecados de plantas, la mayoría ecuatorianas, junto con otra documentación gráfica y escrita asociada, fue una contribución excepcional que enriqueció este proyecto de flora. Aparte del herbario y de un grupo de diseños de plantas en acuarela, también se debe a Caldas la importante colección de impresiones
\end{abstract}

* Real Jardín Botánico RJB-Csic, científico titular, vicedirector de Colecciones, Departamento de Biodiversidad y Conservación. Plaza de Murillo 2, 28014 Madrid, España. Doctor en Biología Vegetal, Universidad de Salamanca (1993). Profesor Asociado (1991-2011) del Instituto de Ciencias Naturales de la Universidad Nacional de Colombia y director del Herbario Nacional Colombiano (1995-2000). Investigación en sistemática y biogeografía de angiospermas neotropicales y en flora de Colombia y coordinador de la Flora de Mutis. Ha publicado 101 artículos científicos y descrito 130 nuevos táxones de plantas. Miembro correspondiente de la Academia Colombiana de Ciencias Exactas, Físicas y Naturales desde 1999. jlfernandeza@rjb.csic.es 
naturales en papel que se conserva en el Archivo de la Expedición del Real Jardín Botánico. En las más de 800 impresiones oectypas se encuentran representadas plantas de 145 familias de helechos y angiospermas. Su estudio nos va a permitir recrear la composición vegetal de algunos sectores del altiplano ecuatoriano. Para poner de manifiesto en qué modo contribuyó a los herbarios y la iconografía de la Flora de Bogotá, el trabajo botánico adelantado por Caldas, se analizó en detalle la familia de las labiadas. Esta familia cuenta con 30 especies ilustradas y llega a 47 el número de las conservadas en el herbario de la Expedición, 20 de las cuales son especies ecuatorianas aportadas por Caldas. Por otra parte, un total de 21 especies de labiadas ecuatorianas que iban a formar parte de la Flora Quitoensis de Caldas quedaron plasmadas en este sistemático y ordenado trabajo de impresión natural.

\section{Caldas y la botánica, una afición tardía}

Francisco José de Caldas (1768-1816) inició el siglo XVIII ejerciendo la abogacía y viajando entre Popayán y Ecuador, para atender negocios de familia que demandaban de sus buenos oficios en la materia. Sin embargo, en lo que a botánica se refiere, en esta época contaba solo con una formación muy básica y en buena medida autodidacta. En la correspondencia de Caldas entre los años 1799 y 1801 dirigida a sus allegados, dejó constancia palpable del renovado interés y dedicación al estudio del mundo vegetal, campo que amplió su ansia de conocimiento del entorno natural. Los progresos fueron sin duda facilitados por el estudio minucioso de las obras de los botánicos hispanos (Quer, Ortega, Palau) que llegaron a sus manos a través de M. María Arboleda, S. Arroyo y Camilo Torres. Fueron ellos los que también compartieron sus primeros pasos en la preparación y estudio de algunos esqueletos de especímenes botánicos payaneses, que a la postre llegarían también hasta las manos de Mutis (San Pío, 1995; Díaz Piedrahita, 1997).

Fue en 1801, poco después de establecido un primer contacto epistolar con José Celestino Mutis (facilitado por Camilo Torres), cuando Caldas emprendió por sugerencia de Mutis un concienzudo trabajo botánico al sur del virreinato. También seguía añadiendo valiosas adquisiciones bibliográficas que estudiaría con el mayor interés, como fue el caso de la clásica Philosophia botanica de Linneo (1792), regalo que tanto agradeció a Mutis. Por su parte, el casual arribo 
de Humboldt y Bonpland a territorio ecuatoriano después de su paso por la Sabana de Bogotá, representó para Caldas otra fuente invaluable de información botánica, a través de las nuevas obras de los científicos viajeros, a las que tuvo libre acceso. El contacto permitió además ampliar los conocimientos y métodos de preparación de especímenes a través de la instrucción directa recibida de Bonpland, persona curtida en la botánica, durante los trabajos conjuntos en los meses de febrero y marzo de 1802.

Por otra parte, al ser nombrado por Mutis en mayo de 1802, botánico adjunto de la Real Expedición Botánica, Caldas abordaría este nuevo empeño con especial dedicación. Prueba de ello es la rica correspondencia de estos años dirigida a José Celestino Mutis, en la que, a la vez que demandaba materiales para la recolección e instrucciones referentes al detallado estudio de las quinas, transmitía algunos avances sobre trabajo desempeñado y perfilaba también nuevos proyectos. Esto se traduciría años más tarde en una contribución muy valiosa en pliegos de herbario, descripciones e ilustraciones esquemáticas de las plantas de Ecuador, a la gran empresa de la Flora de Bogotá que Mutis dirigía desde hacía ya varios lustros.

\section{Viajes, recolectas y reconocimientos llevados a cabo en Ecuador}

Entre 1801 y 1806 los viajes o expediciones de recolección de Caldas - principalmente en territorio ecuatoriano- fueron intensos y muy fructíferos en resultados. Así consta en sus relaciones de viajes (publicados tardíamente en el siglo $\mathrm{xx}$ ) y en sus manuscritos sobre la nivelación de las quinas y otras plantas, que solo en parte lograría publicar en vida, en los años subsiguientes a sus expediciones. En 1802, en una de sus cartas a Humboldt, hace referencia a las intensas recolecciones en la región de Ibarra y al trabajo botánico que llenaba entonces sus ocupaciones. En este escrito con un tono modesto y aparentemente resignado, quizá propiciado por el tipo de interlocutor al que iba dirigido, entre otros aspectos, comentaba:

Es verdad que la botánica hace hoy mi primera ocupación, porque el señor Mutis así lo ha querido y el plan de mis trabajos en este género es inmenso. [...] me he visto precisado a no dejar vegetal ninguno en el campo, describirlos todos, esqueletarlos todos, y diseñar los que no estén en mis miserables libros. 
Un botánico experimentado desecharía todo lo conocido y solo aplicaría su trabajo a lo nuevo y desconocido; pero yo que apenas conoceré 3-400 géneros me veo en la triste necesidad de trabajar aun lo más vulgar y conocido temiendo dejar algo que merezca saberse. Este inmenso material que crece por momentos es inútil entre mis manos; [...] En enero próximo haré mi primera remisión de por lo menos mil esqueletos. (Caldas, 1978, p. 210)

Muchos de los escritos botánicos de Caldas estaban orientados a la catalogación detallada de las distintas plantas, los usos y el hábitat climático donde crecían en las diferentes regiones que iba recorriendo. Pero lo que inició como un trabajo centrado en la caracterización de las especies útiles y sus zonas óptimas de cultivo en la Real Audiencia de Quito se traduciría después en un ambicioso plan de reconocimiento y estudio de toda la flora silvestre de aquella región de Ecuador. El volumen de muestras de herbario manejadas fue considerable y otro tanto pudiera decirse del gasto de papel utilizado para procesarlas y para la realización de diseños y ectypas. Constancia de ello se deja en la correspondencia mantenida por Caldas con varios de sus amigos y colaboradores en este periodo 1801-1805 (San Pío, 1995). Fueron más de cuatro años recabando información rigurosa sobre las plantas de varios sectores; de Ibarra al Imbabura en 1802 y de Ibarra hasta Malbucho en el Pacífico en 1803. Y después, de nuevo en busca de quinas a través de Latacunga, Ambato, Cuenca y Loja en 1804, para emprender por último el camino de regreso a Popayán y a Bogotá en 1805. El aporte de cerca de 6000 pliegos de plantas disecadas, recolectadas en territorio ecuatoriano, al Herbario General de la Expedición en Bogotá fue una contribución excepcional que aún hoy seguimos estudiando.

\section{La Cinchografia de Caldas y la Historia de los árboles de la quina de Mutis}

En su relación de viajes y en las notas botánicas que nos han llegado se incluye información valiosa de tipo etnobotánico sobre muchas plantas útiles y cultivadas. Aparte de la proyección sobre botánica económica que muestran muchos de sus escritos, incluyen también información ecológica y climática relacionada que es presentada de manera sistemática y original. Un ejemplo de ello es la nivelación de 30 plantas en Imbabura llevada a cabo en 1802 (figura 1) y dada a conocer mucho más tarde (Díaz Piedrahita, 1991, p. 50; 1992, p. 371). A pesar de no 
poder asignar identificación a buena parte de las plantas (que él consideraba acertadamente como nuevas), el empleo de nombres vernáculos en muchos casos y la asignación de números consecutivos le permitían hacer seguimiento de sus colecciones en diarios, notas, mapas, ectypas y exicados vegetales. Especialmente relevante y detallado fue su estudio de la Cinchografía o geografía de los árboles de la quina, donde describió con gran detalle las cinco especies de quina encontradas en Ecuador. Esta información acopiada por Caldas enriquecería en gran manera y ayudaría a completar la redacción del Estudio de los árboles de la quina en el que desde hacía mucho tiempo venía trabajando José Celestino Mutis, y que se finalizó después de su muerte con la contribución de Sinforoso Mutis y de Caldas (figura 2).

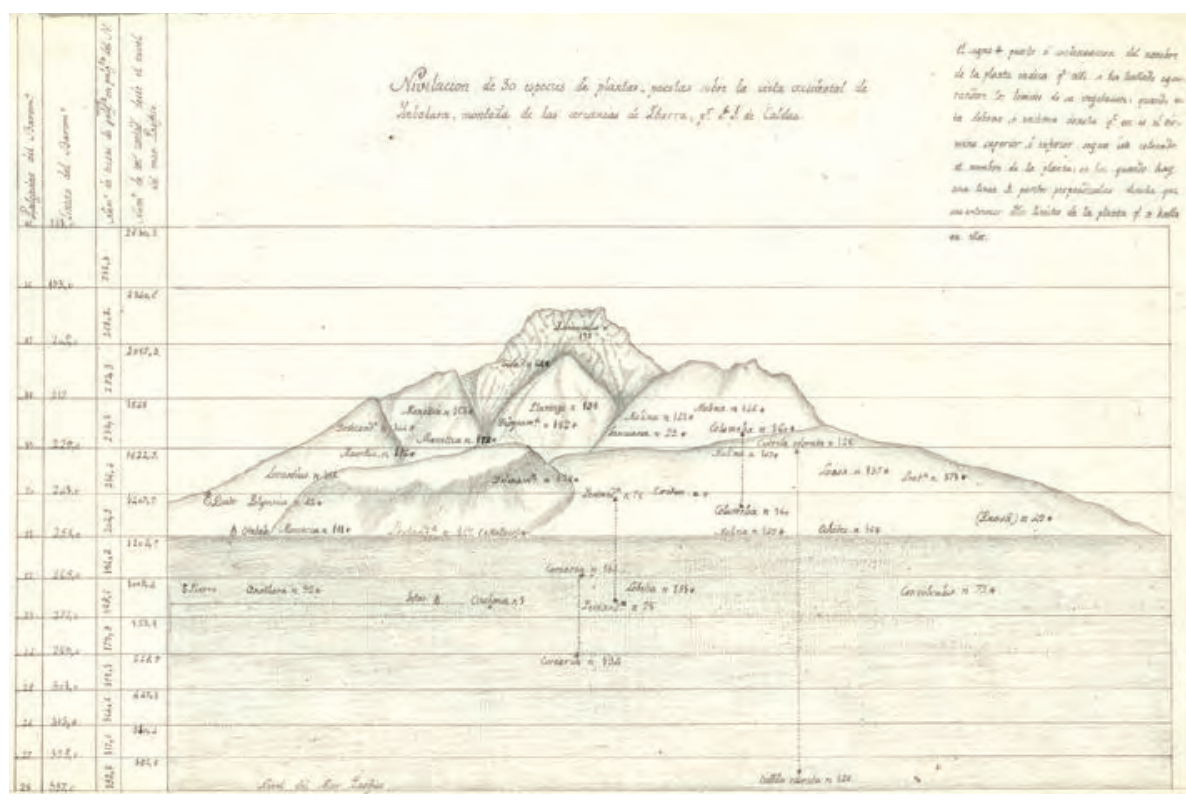

Figura 1. Nivelación de 30 especies de plantas, puestas sobre la vista occidental de Imbabura, montaña de las cercanías de Ibarra, Ecuador. Por F. J. de Caldas. Original del Archivo del Real Jardín Botánico de Madrid. ARJB M00529. 


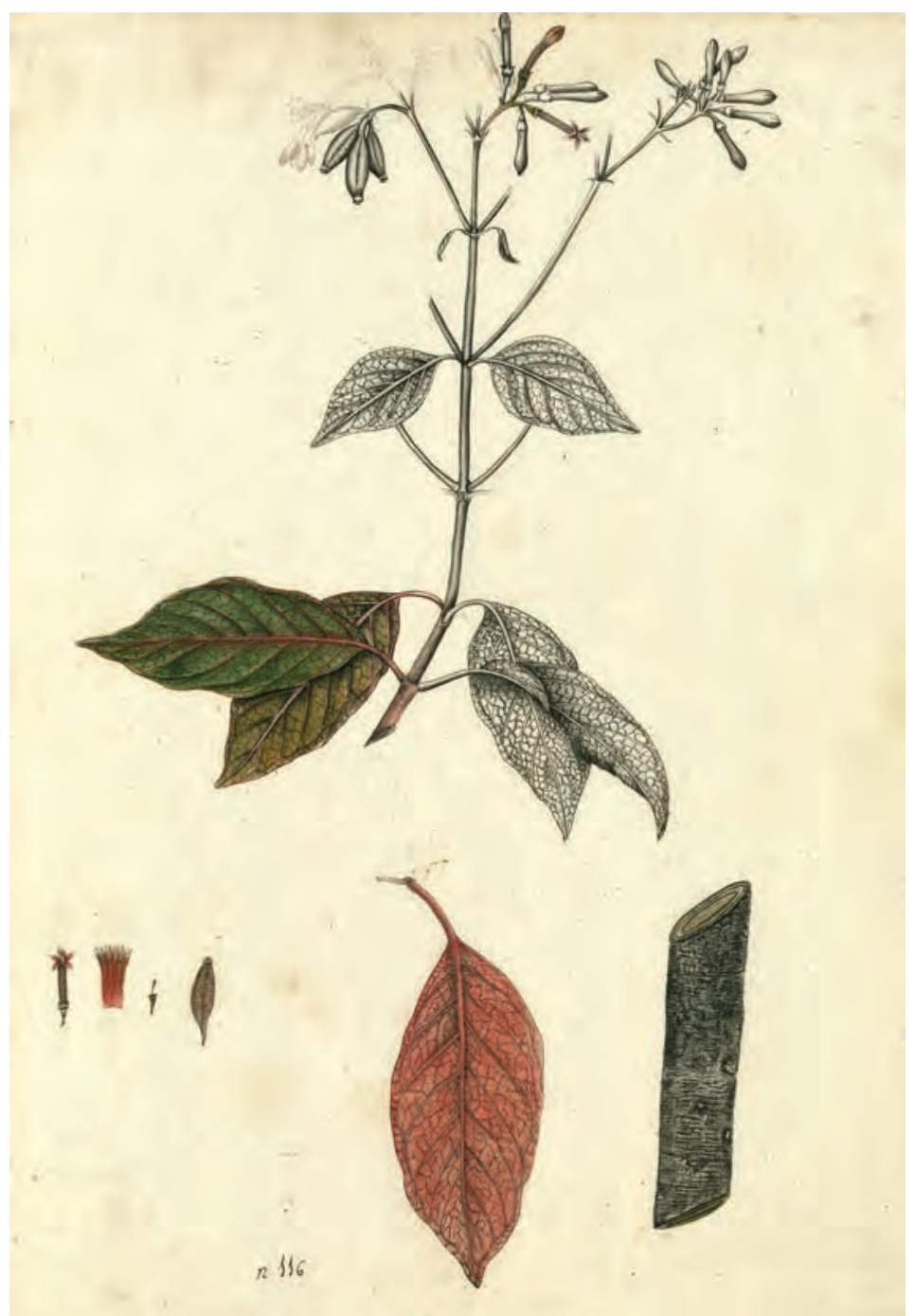

Figura 2. Cinchona pubescens Vahl., Rubiaceae. Original del Archivo del Real Jardín Botánico de Madrid. ARJB B00208.

\section{Géneros nuevos de la Flora de Bogotá y el Semanario del Nuevo Reino de Granada}

Por otra parte, en un intento de mostrar y validar los nuevos géneros que desde hacía muchos años se acopiaban en los manuscritos y herbarios de la Expedición Botánica, Caldas y Sinforoso Mutis se impusieron la tarea urgente de publicarlos formalmente. El medio elegido para darlos a conocer fue el Semanario del Nuevo 
Reino de Granada, revista donde a la vez explicaban y justificaban esta reorientación práctica de los trabajos de la Expedición. Estos nuevos géneros, con sus nombres dedicados, honraban a las personas que habían tenido que ver directa o indirectamente en los logros de la Expedición. Este es el caso de Ammaria Mutis ex Caldas, Caldasia Mutis ex Caldas, Consuegria Mutis ex Caldas, Lozania Mutis ex Caldas, Pombea Mutis ex Caldas y Valenzuelia Mutis ex Caldas entre otros géneros (figura 4). Como testigo palpable de la proyectada Flora Quitoensis de Caldas nos ha quedado un género de plantas andinas con tubérculos comestibles, Ullucus Caldas (figura 3) que es el nombre científico de la chugua o ulluco $(U$. tuberosus Caldas) descrito en una de las entregas publicadas en este Semanario científico (Caldas, 1809, p. 185).

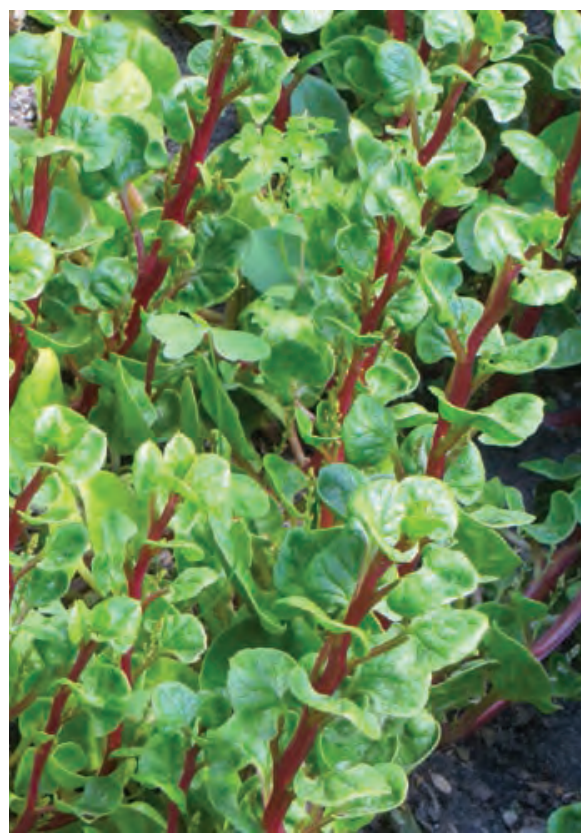

Figura 3a. Ullucus tuberosus. Imagen 4860

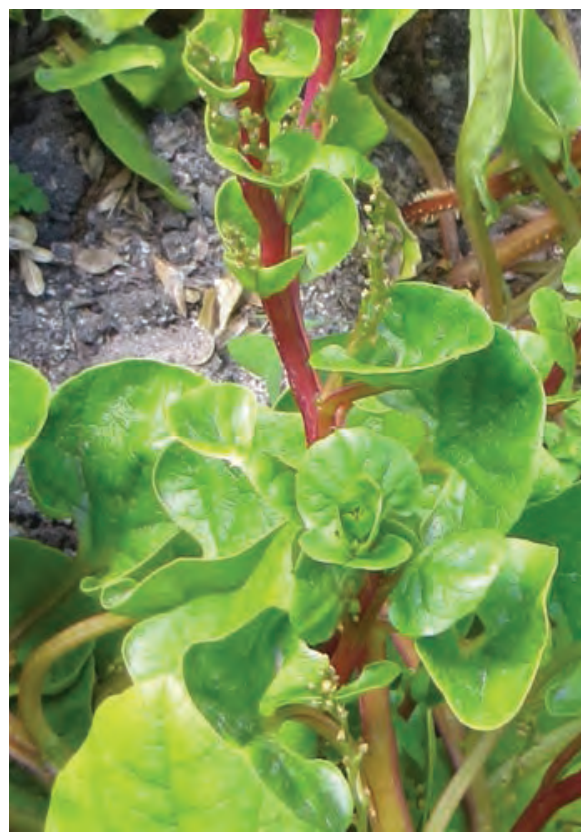

Figura 3b. Ullucus tuberosus. Imagen 4861

Figura 3. Ullucus tuberosus Caldas, Basellaceae (a y b). Fotografía J. L. Fernández Alonso. Planta cultivada en la Terraza de los Cuadros del Real Jardín Botánico de Madrid. 


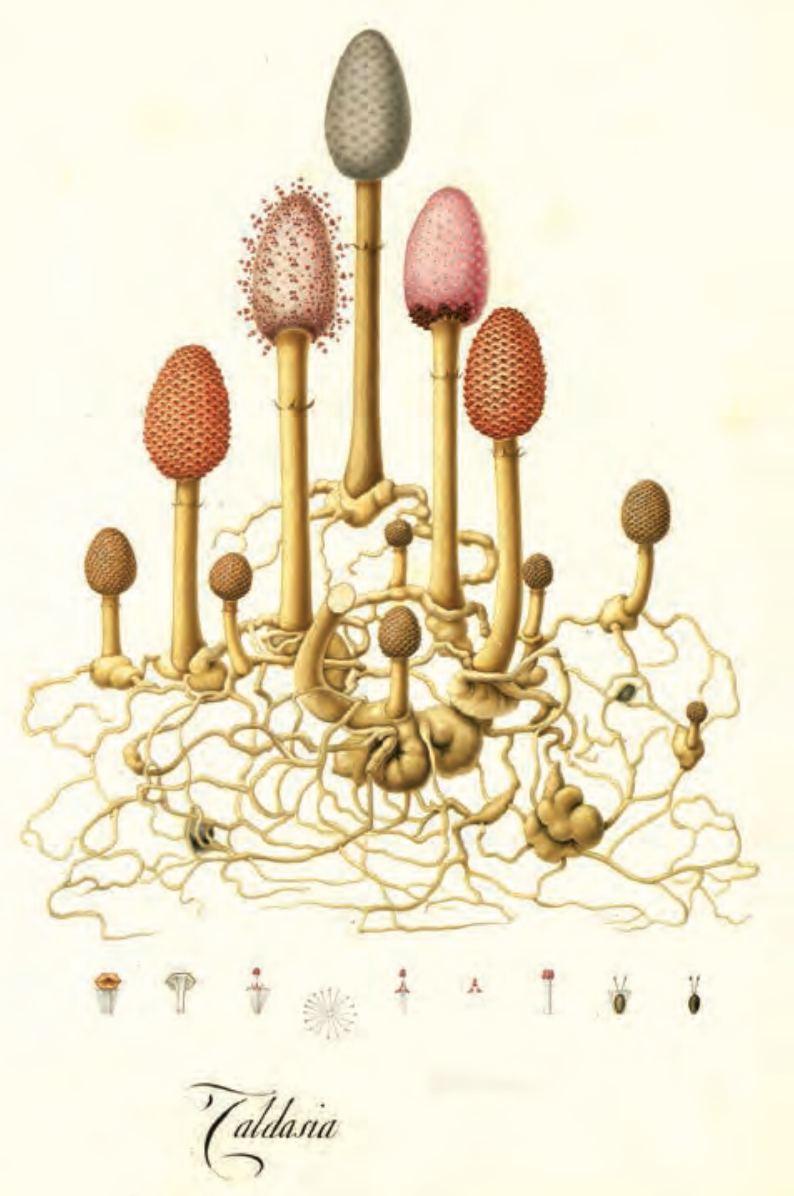

Figura 4. Helosis cayanensis (Sw.) Spreng., Balanophoraceae = Caldasia Mutis. Original del Archivo del Real Jardín Botánico de Madrid. ARJB A0092.

\section{Dando forma a una flora. Los materiales para la Flora Quitoensis}

Sin duda, aparte de su excelente herbario y de un pequeño grupo de diseños de plantas nuevas realizados en acuarela, entre los que se encuentra la representación de un gualanday de la región ecuatoriana de Loja (figura 5), la rara bignoniácea Jacaranda sparrei A. H. Gentry (Fernández Alonso, 1992, p. 39) y la planta medicinal Cavendishia quereme (Kunth) Benth. \& Hook F., ilustrada ya en Popayán, al concluir su periplo ecuatoriano (figura 6); uno de sus trabajos más concienzudos y desconocidos hasta fechas recientes es su gran colección de 
más de 850 impresiones de plantas o ectypas. Se trata de un trabajo ejecutado con gran calidad técnica, que nos permite recrear hoy las principales plantas de los altiplanos de Ecuador, con base en las precisas impresiones obtenidas en tinta sobre papel de las diferentes plantas prensadas. Fue una recolección sistemática y cuidadosa que abarca 145 familias de plantas vasculares (helechos, gimnospermas y angiospermas) y que nos da una idea de la seriedad con que Caldas se tomó este trabajo. En ella se encuentran representados todos los biotipos (bejucos, epífitas, pequeñas hierbas, árboles, etc.) y hábitats, incluyendo plantas acuáticas y también algunas cultivadas y sus malas hierbas acompañantes de los campos.

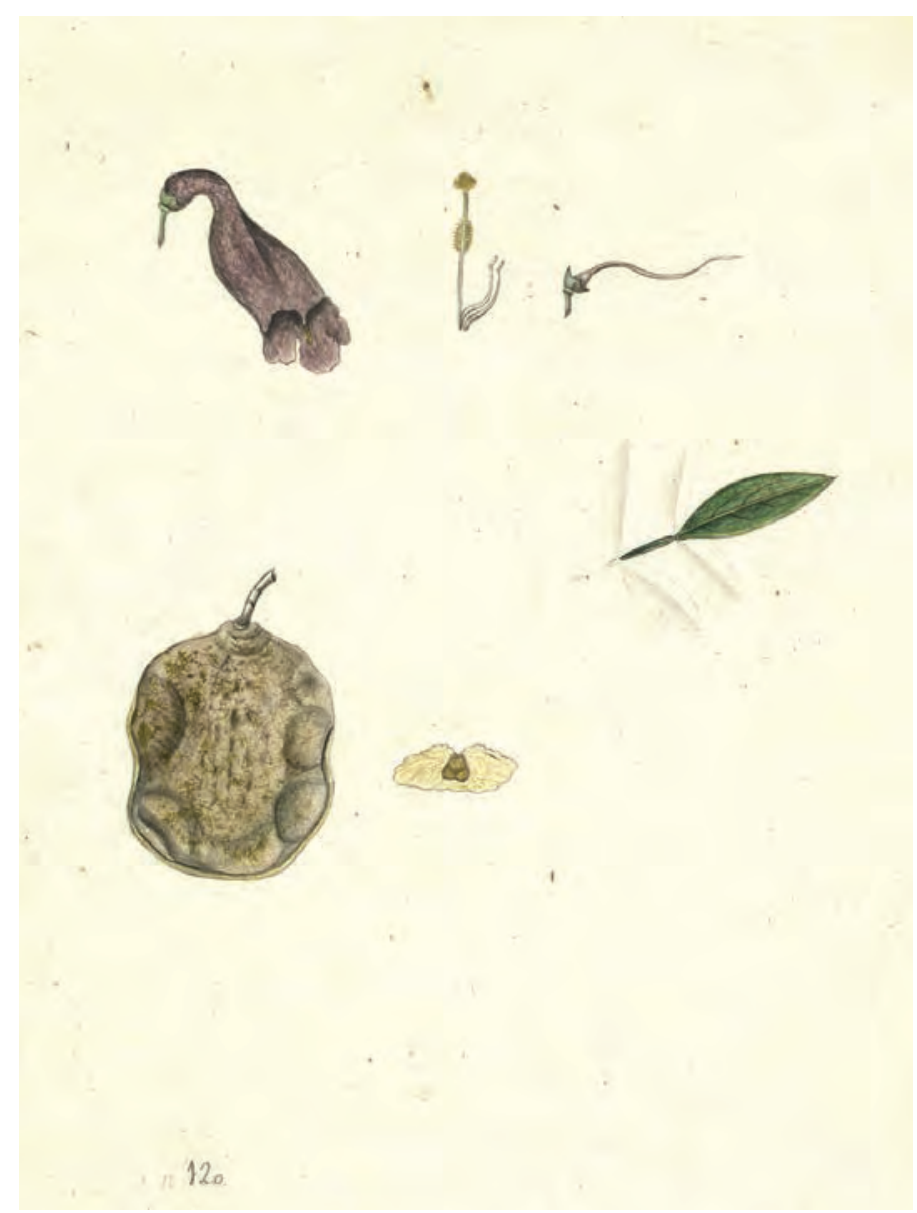

Figura 5. Jacaranda sparrei A. H. Gentry, Bignoniaceae. Acuarela correspondiente al grupo de Diseños de Caldas elaborados en Ecuador. Original del Archivo del Real Jardín Botánico de Madrid. ARJB B00209. 


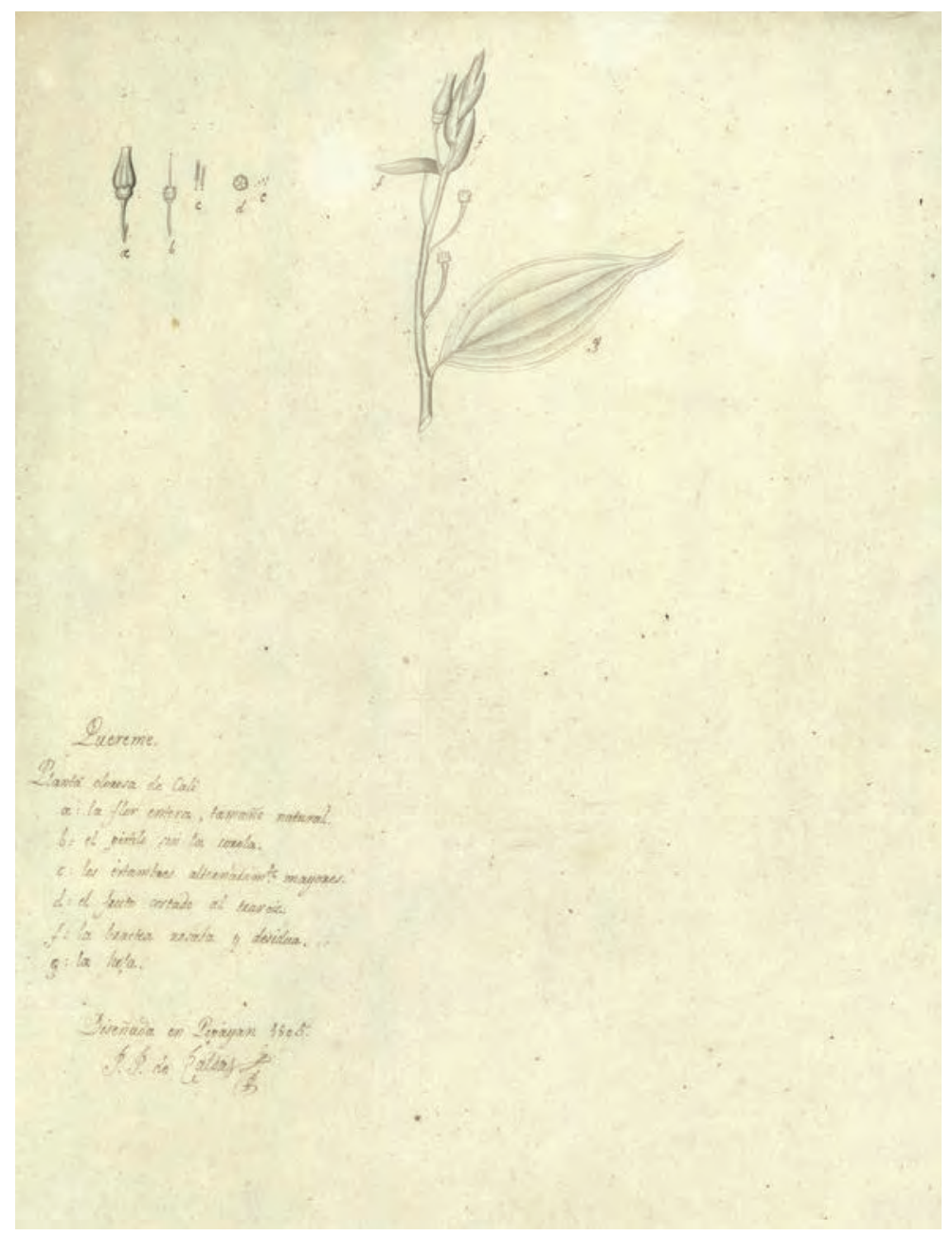

Figura 6. Cavendishia quereme (Kunth) Benth. \& Hook F., Ericaceae. Acuarela correspondiente al grupo de Diseños de Caldas. Original del Archivo del Real Jardín Botánico de Madrid. ARJB B00502.

\section{Un censo preliminar de familias, géneros y especies en las ectypas de Caldas}

Caldas hizo contadas referencias a su colección de ectypas en cartas o informes relacionados con el material acopiado en Ecuador y entregado en Bogotá al final de su viaje. Con posterioridad, hubo escasas alusiones indirectas a esta colección de impresiones naturales, representaciones siempre asociadas a especies nativas de la flora ecuatoriana, ilustradas más tarde en Bogotá con base en la documentación 
aportada por Caldas. Este es caso de la compuesta Hymenostephium quitensis (Benth.), E. E. Schil \& Panero, para cuya elaboración se utilizó la ectypa número 48 (Díaz Piedrahita, 2009, p. 61). Un dato revelador que pone de manifiesto el cuidado y el método con que Caldas adelantó el inventario y estudio de la Flora Quitoensis es que aún hoy podemos establecer la correspondencia entre muchos de los pliegos, los diseños e impresiones naturales en papel por la numeración consecutiva original que han conservado. Del mismo modo, algunos de estos números aparecían también en las anotaciones de plantas que hacen parte de los diarios de viajes y de las representaciones esquemáticas de algunas zonas recorridas, elaboradas en su estudio de nivelación de las plantas, como es el caso de las correspondientes al Monte Imbabura.

Como avance del estudio que actualmente se lleva a cabo en la identificación taxonómica de esta colección de ectypas (Fernández Alonso, en prep.), observamos en nuestros datos que las familias mejor representadas son básicamente también las familias más ricas de esta flora, lo que refleja el buen trabajo realizado. Así, de las compuestas o asteráceas, la familia más diversa en esos ambientes, se realizaron 111 ectypas que corresponden a 40 géneros; le siguen las leguminosas con 27 géneros y 65 ectypas, que es otra de las familias más importantes en la flora nativa. En tercer lugar, las malváceas —en su circunscripción ampliada actual-, con 27 géneros y 49 ectypas, y en cuarto las rubiáceas, familia siempre rica en gradientes andinos (16 géneros, 46 ectypas). Nos llamó la atención el importante grupo de ectypas realizadas de las poáceas o gramíneas (20 géneros y 45 ectypas), al tratarse de plantas que presentan inflorescencias relativamente uniformes y flores muy poco llamativas. Esta es una muestra más del riguroso y metódico trabajo llevado a cabo por Caldas en este sector del virreinato, bajo su jurisdicción por encargo de José Celestino Mutis. La única excepción la constitur yen las orquídeas, que ocupan el séptimo puesto (con 12 géneros y 25 ectypas), a pesar de ser la familia más diversa de la Flora de Ecuador. Pero se trata en nuestra opinión de una excepción previsible, ya que muchas de las orquídeas de la flora ecuatoriana se encuentran como epífitas en hábitats difícilmente accesibles, lo que hace que la recolección y estudio de esta familia, tanto en la época de Caldas como en nuestros días, sea un proceso gradual y dispendioso (Neill, 2012, p. 8).

\section{Plantas arvenses y otros avances relevantes}

Las plantas de Ecuador que hoy cuentan con láminas policromas que fueron elaboradas en Bogotá bajo la supervisión de Caldas suman más de 30 especies. 
Aparte de las Labiadas que se mencionarán más adelante, las plantas con ilustraciones de gran calidad corresponden a géneros de otras diversas familias. Las más numerosas sin duda son las láminas de compuestas de los géneros Baccharis L., Chuquiraga Juss., Dasyphyllum Kunth, Jungia L. f. y Loricaria Wedd. (figura 7), que ya fueron cuidadosamente tratadas en los tomos publicados de la Flora de Mutis (Díaz Piedrahita, 2001; 2009). En todos los casos mencionados se cuenta hoy con los pliegos de herbario de referencia de las plantas y con las correspondientes ectypas reconocibles. Otras especies representadas son: Wigandia urens (Ruiz \& Pav.) Kunth (hidrofiláceas) con una excelente lámina, sus bocetos y anatomías; una especie de Nototriche (malváceas), endémica de los volcanes de Ecuador (figura 8); un Piper L. (piperáceas) del Pacífico de Ecuador; dos especies de Lycopodium L. y Vittaria Sm. (pteridófitas) y una especie de Colletia Comm. Ex Juss. de las ramnáceas (figura 9), género sureño que no alcanza a Colombia en su distribución.

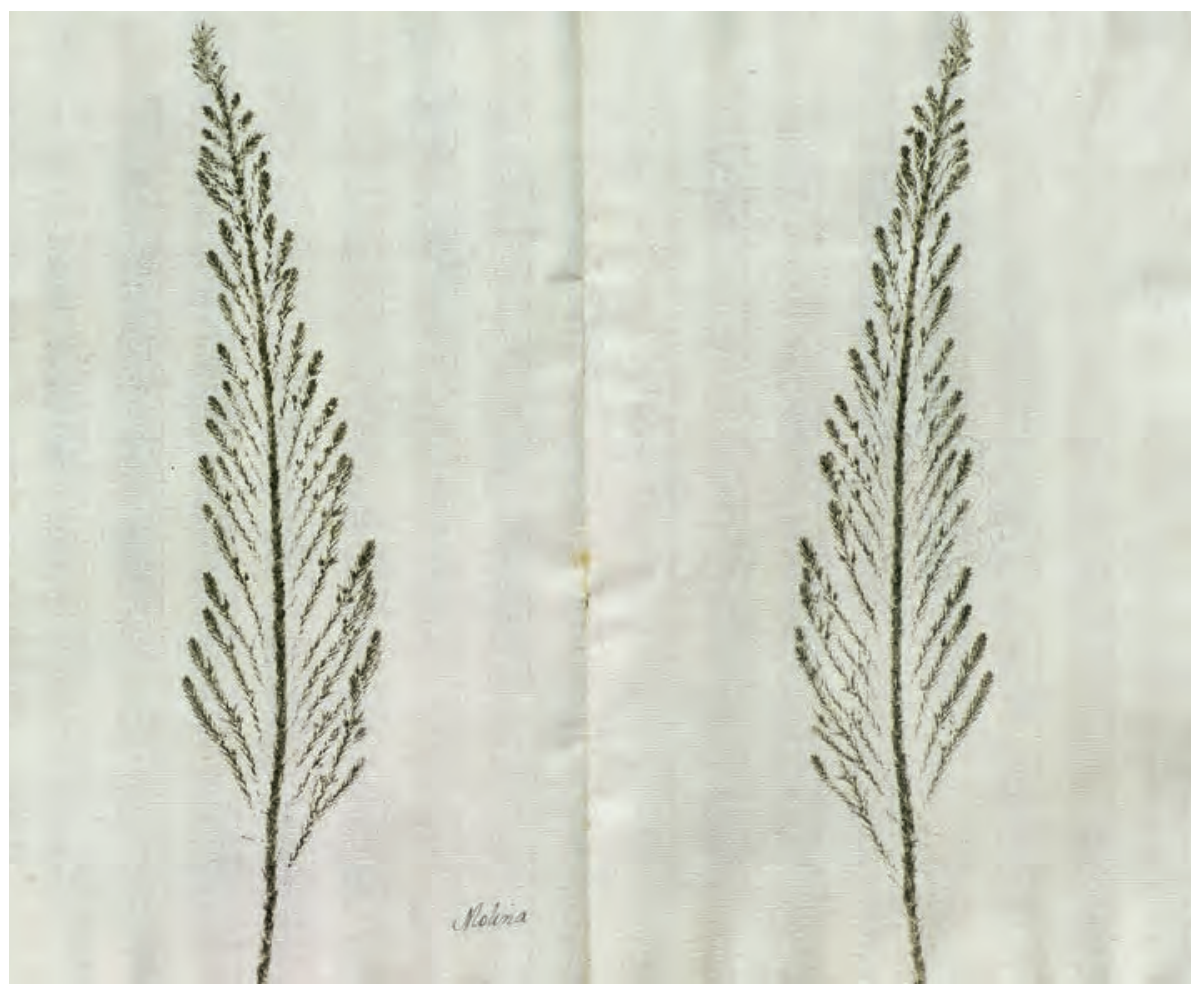

Figura 7. Loricaria thuyoides (Lam.) Sch. Bipp., Asteraceae. Impresión natural o ectypa.

Original del Archivo del Real Jardín Botánico de Madrid. AJB03 ectypa s2 253. 


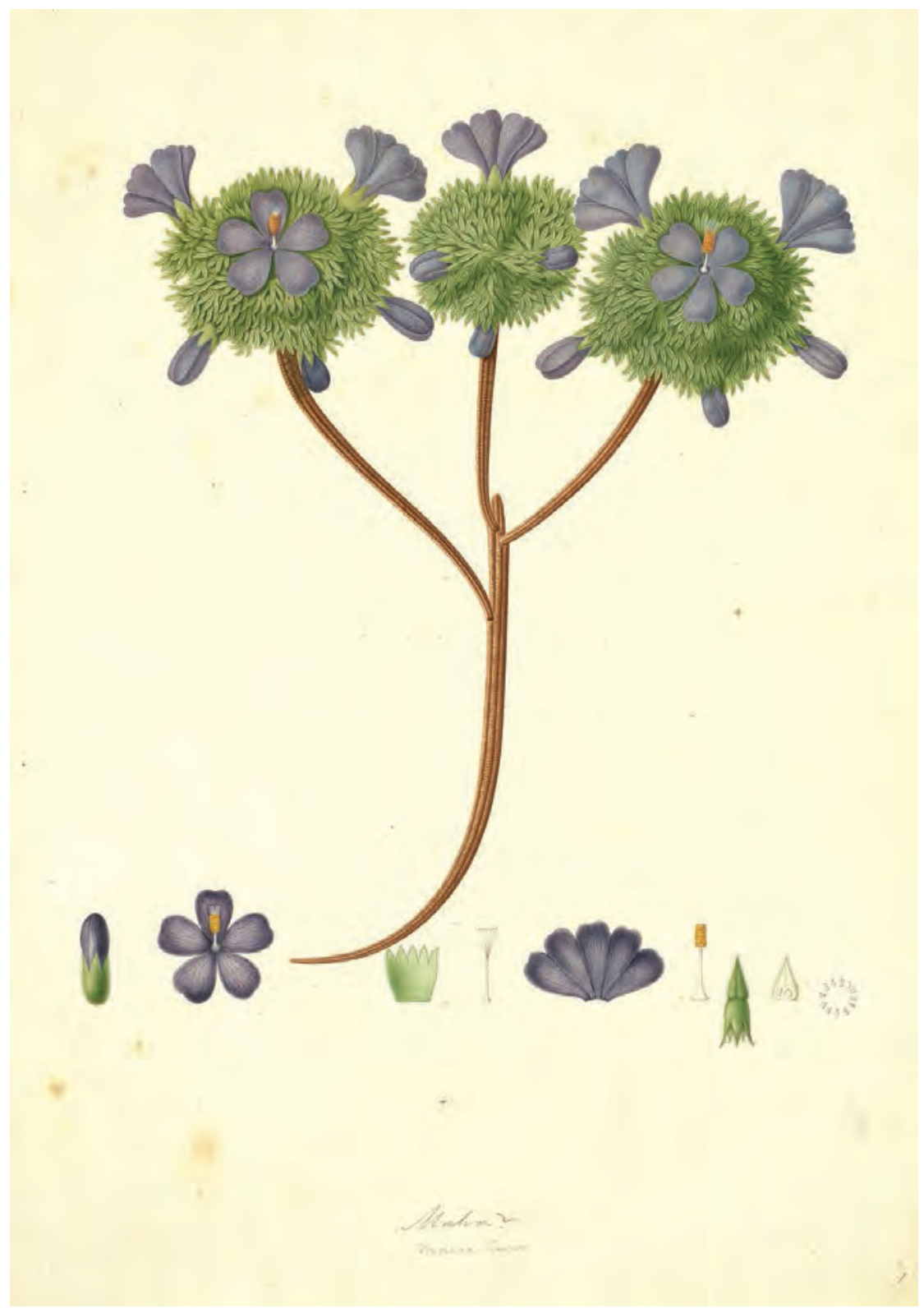

Figura 8. Nototriche jamesonii A. V. Hill., Malvaceae. Original del Archivo del Real Jardín Botánico de Madrid. ARJB A02117. 


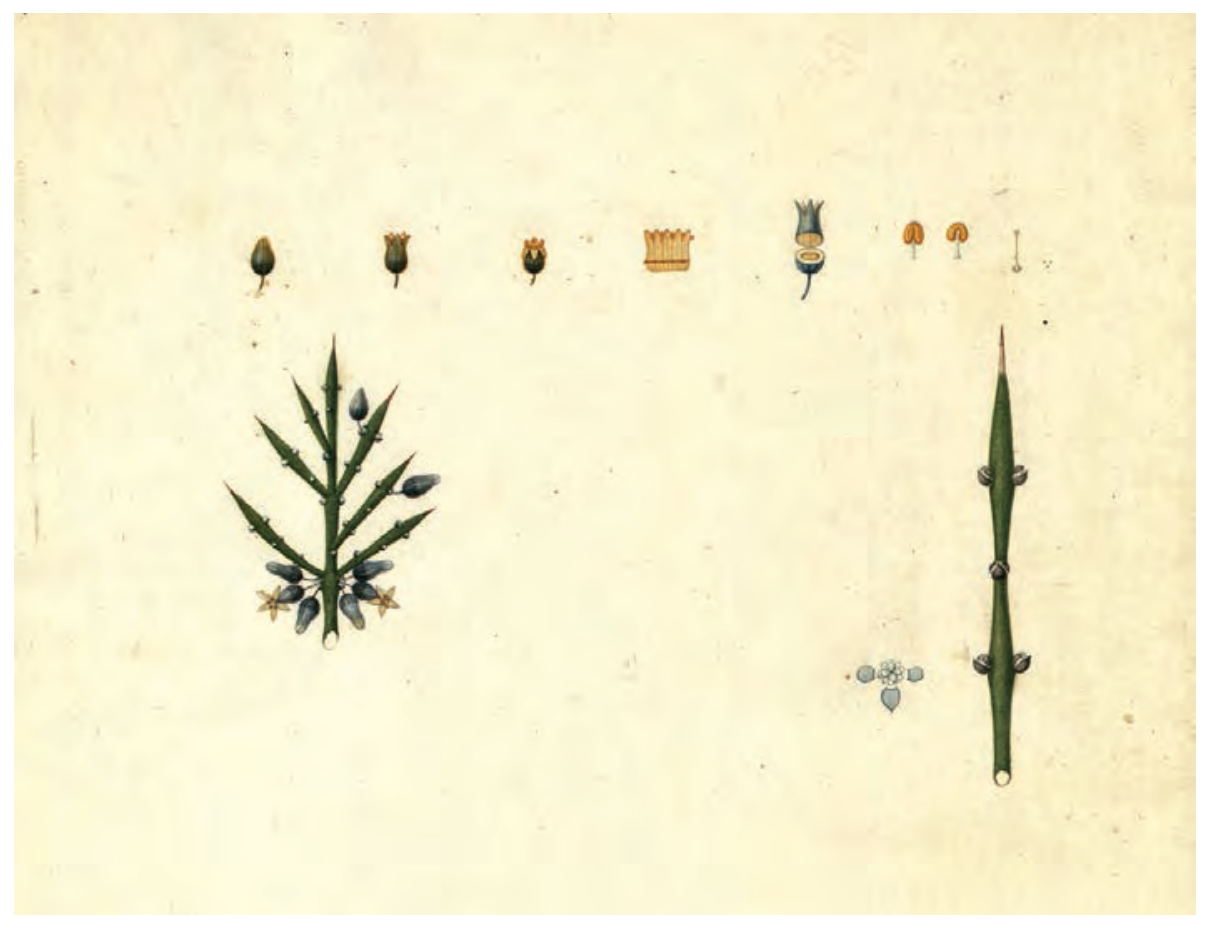

Figura 9. Collettia spinosa Lam., Rhamnaceae. Original del Archivo del Real Jardin Botánico de Madrid. Colección de anatomías. ARJB B00291

Para nuestra sorpresa, entre las plantas cultivadas catalogadas en las ectypas de Caldas, encontramos por ejemplo el garbanzo, género Cicer L. (figura 10) y la alfalfa (Medicago L.). Y son muchas más las dedicadas a la flora arvense de origen europeo que crecen en los cultivos altoandinos. Están representadas por varios géneros de diferentes familias, así:Anagallis L., Capsella Medik., Erodium L’Her., Lepidium L., Linum L., Plantago L., Poterium L. y Spergula L., entre otros. En estas plantas arvenses de Caldas se recoge un registro histórico, el de Plantago afra L. (plantagináceas), un llantén europeo de hojas opuestas (figura 11). Esta especie, que debió de llegar con las semillas de cereal, aún crece en la actualidad en los campos de Ecuador y sigue siendo desconocida en Colombia. Es probable que el reconocimiento de estas plantas arvenses comunes en Europa, que sí aparecían en los libros europeos de botánica manejados por Caldas, tuviera un aliciente adicional para alguien que trataba de consolidar sus conocimientos en botánica. Caldas, en su correspondencia (a Mutis y a Humboldt) se quejaba de la dificultad que tenía para identificar esta rica flora nativa (Ecuador), de la que 
solo conocía algunos cientos de géneros y de la que comentaba acertadamente que la mayor parte de lo que recolectaba eran novedades aún por catalogar y describir (Caldas, 1978, p. 210; San Pío, 1995, p. 8; Díaz Piedrahita, 1997, p. 118).

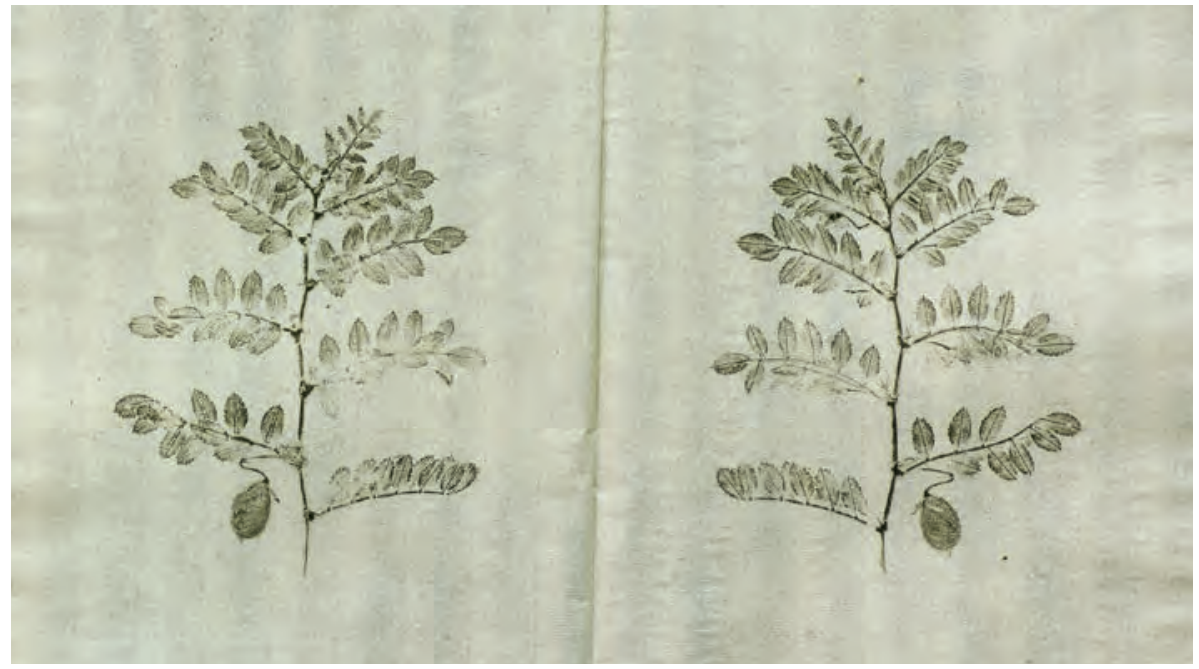

Figura 10. Cicer arietinum L., Fabaceae. Impresión natural o ectypa elaborada por F. J. de Caldas. Original del Archivo del Real Jardín Botánico de Madrid. AJB03 ectypa s194.

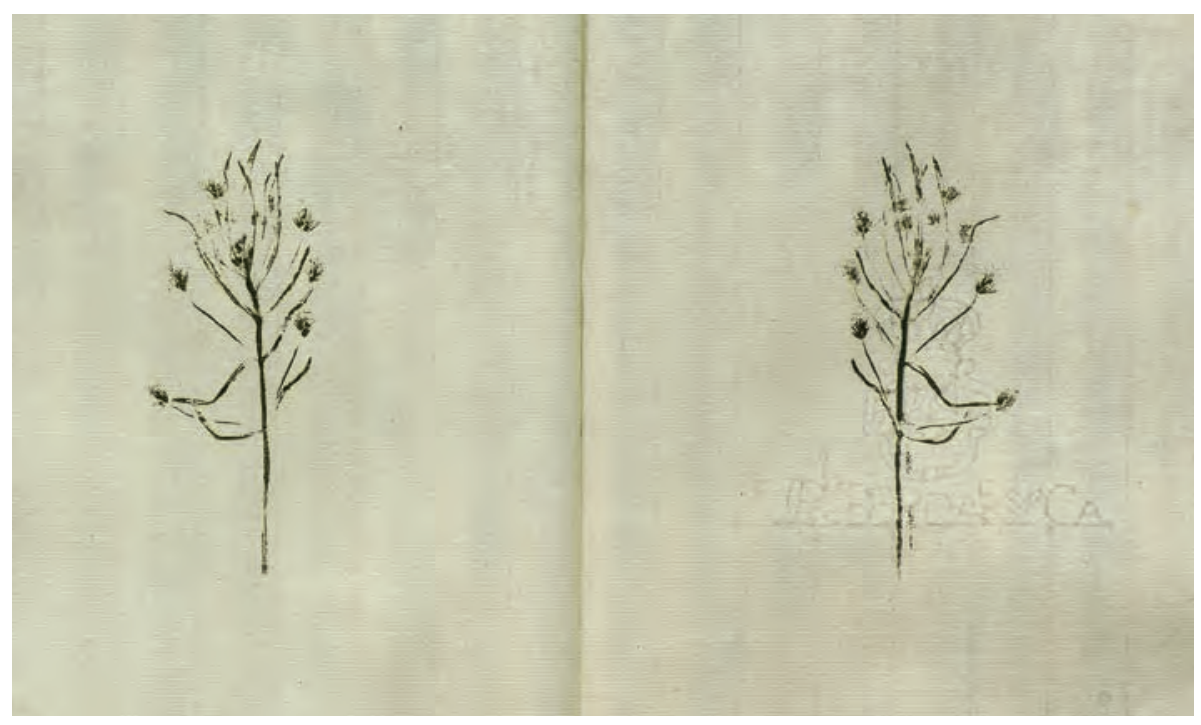

Figura 11. Plantago afra L., Plantaginaceae. Impresión natural o ectypa. Original del Archivo del Real Jardín Botánico de Madrid. AJB03 s1 177. 


\section{Estudio de caso. La familia de las labiadas en la Flora Quitoensis}

Para poner de manifiesto en qué modo contribuyeron las observaciones manuscritas, las impresiones naturales y las plantas desecadas de Caldas a los herbarios y la iconografía general de la Flora de Bogotá, hacemos referencia pormenorizada a las labiadas de la Real Expedición Botánica, que es una de las familias ya estudiadas, que espera publicarse próximamente (Fernández Alonso, 1996). En las láminas de la Expedición se encuentran representadas 30 especies de labiadas, y llega a 47 la cifra de las conservadas en su herbario. De estas especies recolectadas, 17 no fueron ilustradas. Las aportadas por Caldas fruto de sus recolecciones fueron 20 especies ecuatorianas que hoy forman parte del Herbario general de Mutis. Además, un total de 22 especies de Labiadas de Ecuador quedaron plasmadas en la colección de ectypas de Caldas. Estas impresiones en papel, junto con las anotaciones de Caldas y los pliegos de herbario, sirvieron después para la elaboración de varias láminas policromas definitivas de la Flora de Bogotá, en la Casa de la Botánica de Santafé, sede de la Expedición. Este es el caso de Salvia leucocephala Kunth y Satureja jamesonii (Benth.) Briq., especies endémicas de Ecuador (figuras 12 y 14) cuyos pliegos, ectypas y diseños conservan la numeración original asignada por Caldas.

Otro caso significativo es el de algunas especies raras del género Scutellaria, dos de ellas nuevas para la ciencia asociadas a las ectypas y pliegos de Ecuador. Scutellaria pseudocoleus Fern. Alonso (figura 13), que fue descrita a partir de la lámina y el pliego recolectado por Caldas, es una especie medicinal y amenazada del occidente de Colombia y Ecuador (Fernández Alonso, 1990, pp. 106-107; Fernández Alonso y Rivera, 2006, pp. 569-572). Por otra parte, Scutellaria cuatrecasana Fern. Alonso, registrada entre las ectypas de Caldas, es una especie rara que fue nombrada solo en la década de 1990. Del mismo modo, nos quedaron registros de varias especies del género Hyptis Jacq., algunas de ellas como en $H$. florida Benth., H. melissoides Kunth. $y$ H. obtusata Benth. (figuras 15 y 16 ) restringidas al sur de Colombia y Ecuador (Fernández Alonso, 1995, pp. 477-478; Fernández Alonso y Rivera, 2006, pp. 488-490). Satureja jamesonii (figura 14) que solo se encuentra en los volcanes del sur de Colombia y Ecuador, fue magníficamente documentada por Caldas al contar con un diseño esquemático de la planta, una lámina de anatomías, una ectypa y pliegos de herbario. 
Las plantas de Francisco José de Caldas y su contribución a los herbarios y escritos de la Flora de Bogotá

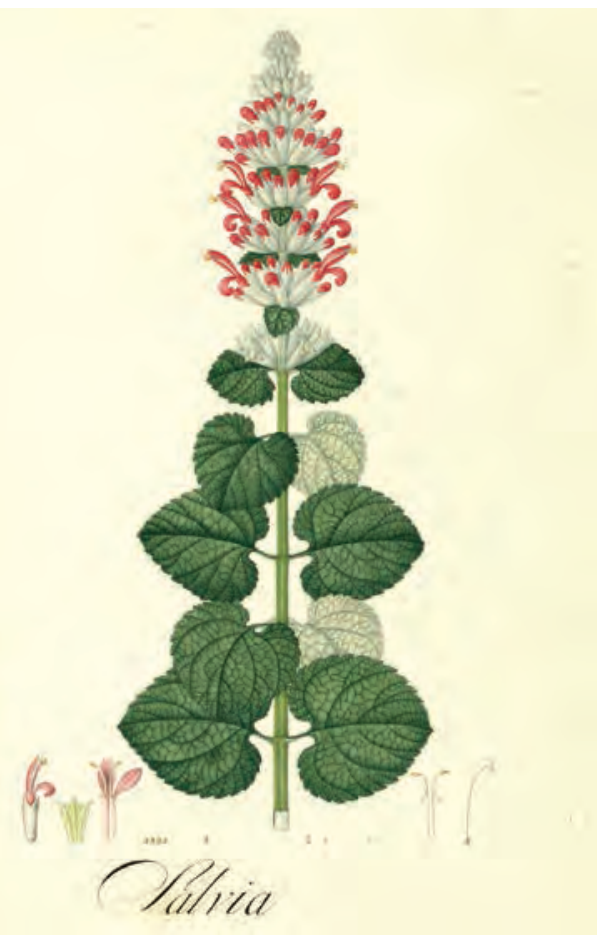

Figura 12a

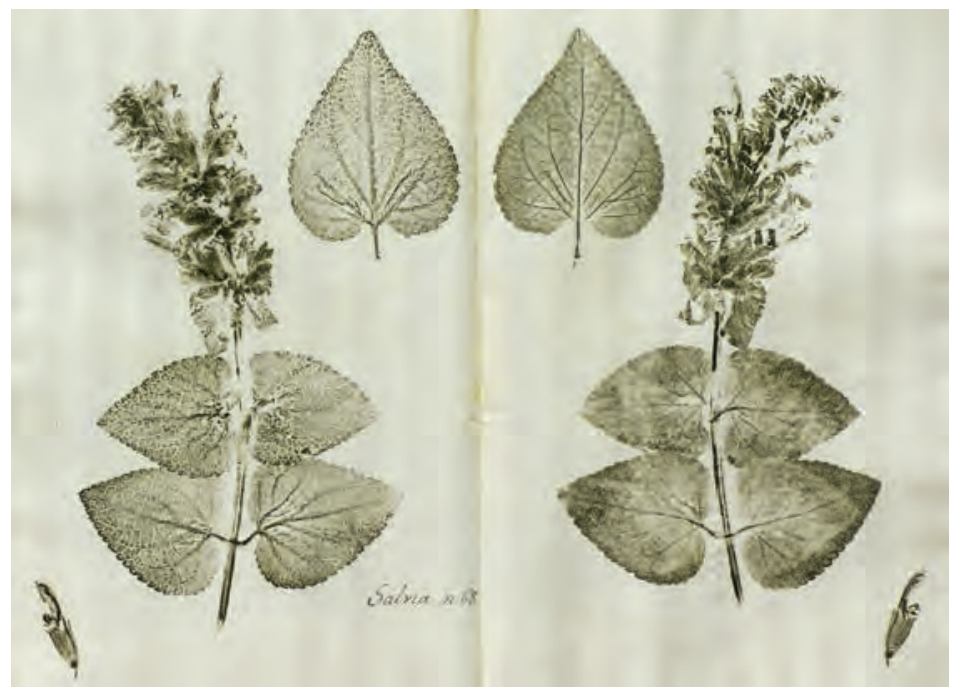

Figura 12b

Figura 12. Salvia leucocephala Kunth, Lamiaceae. 12a. Original del Archivo del Real Jardín Botánico de Madrid. ARJB A01440. 12b. Impresión natural o ectypa elaborada por F. J. de Caldas. AJB03 ectypa s3 35. 


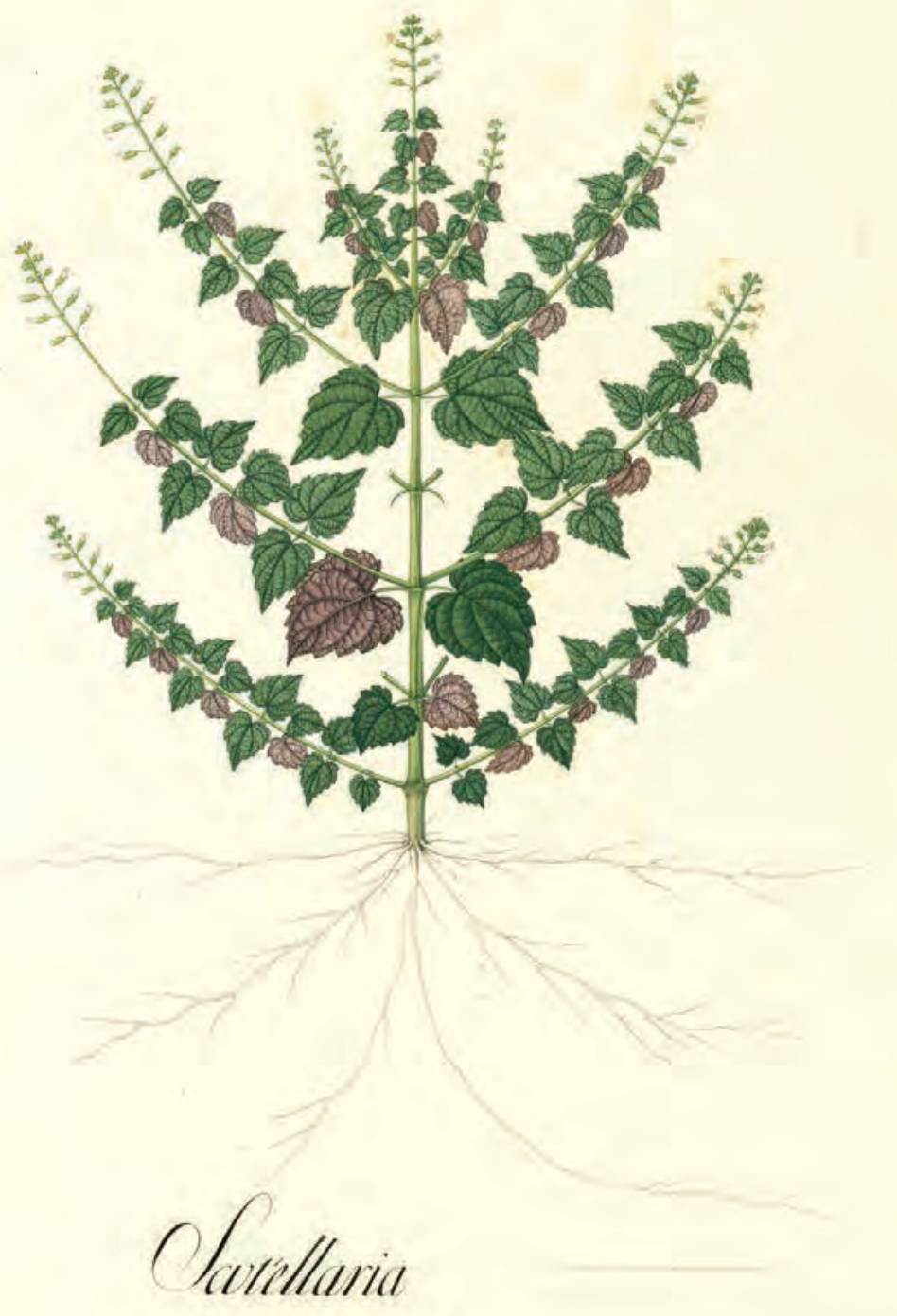

Figura 13. Scutellaria pseudocoleus Fern. Alonso, Lamiaceae. Original del Archivo del Real Jardín Botánico de Madrid. ARJB A01449 


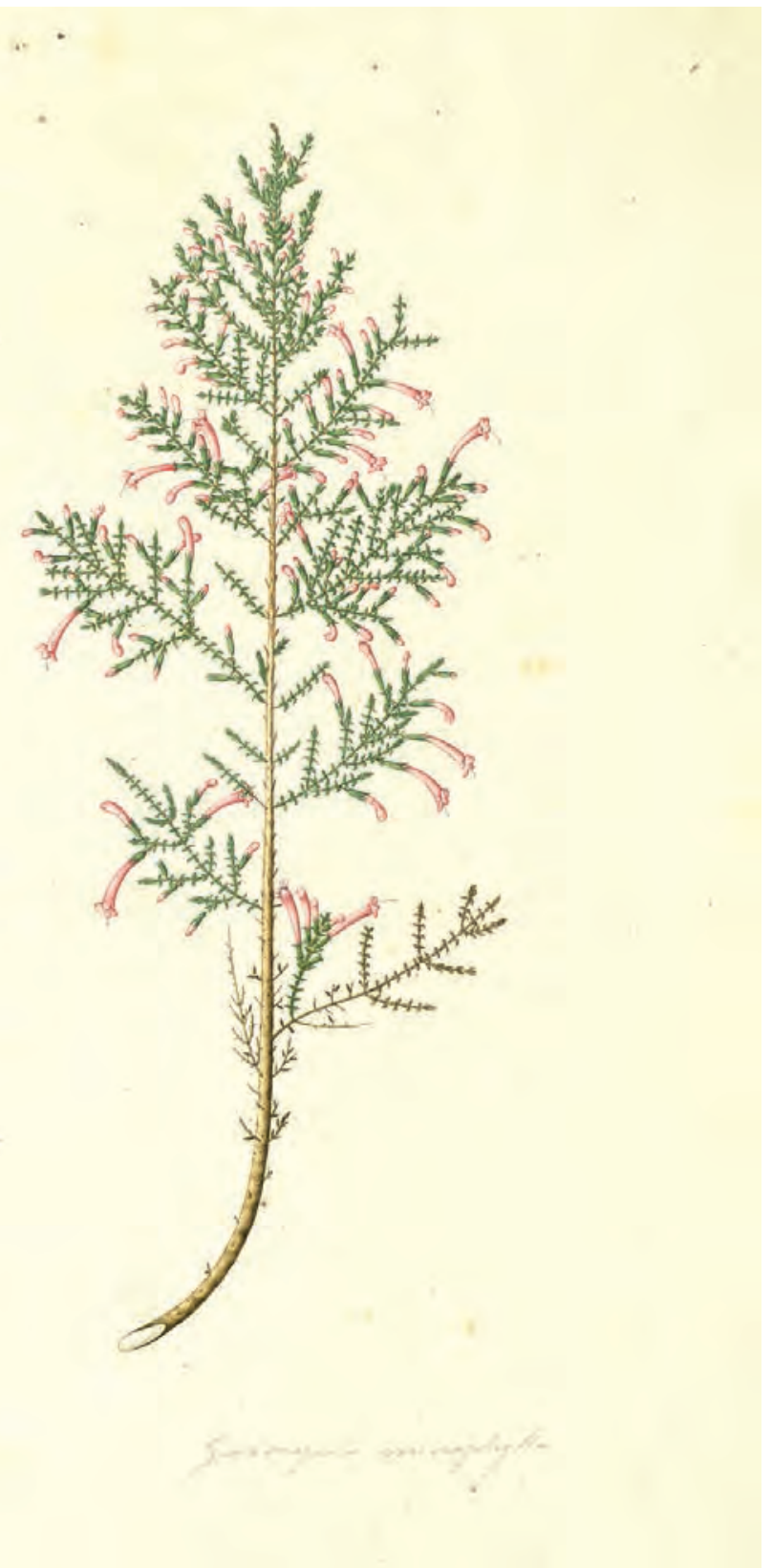

Figura 14. Satureja jamesonii (Benth.) Briq., Lamiaceae. Original del Archivo del Real Jardín Botánico de Madrid. ARJB A01443 


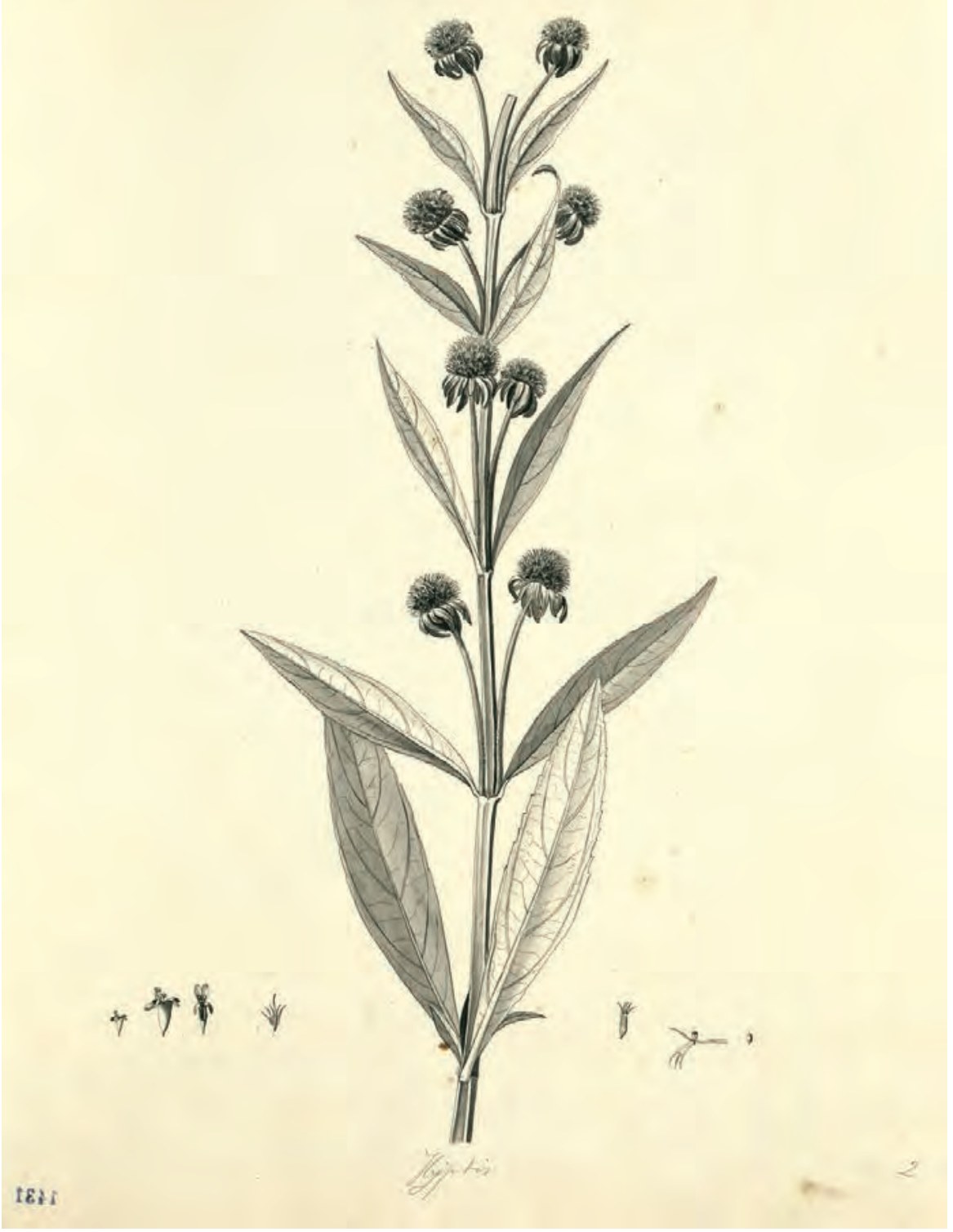

Figura 15. Hyptisflorida Benth., Lamiaceae. Original del Archivo del Real Jardín Botánico de Madrid. ARJB A01431 

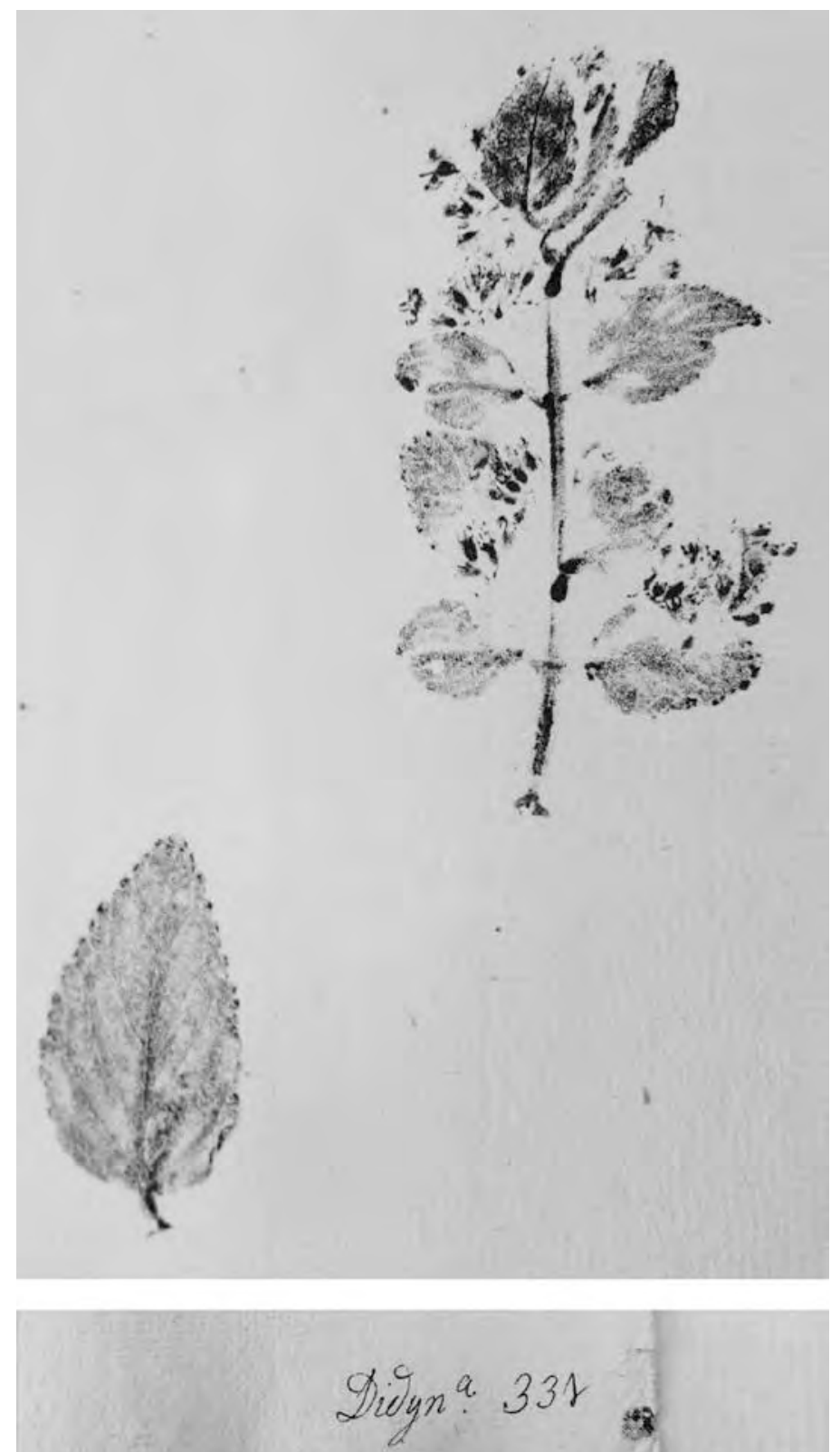

Figura 16. Hyptis melissoides Kunth, Lamiaceae. Impresión natural o ectypa. Original del Archivo del Real Jardín Botánico de Madrid. a). AJB03 ectypa s1 331. b). Detalle de la identificación original de Caldas: "Didyna[mia]. 331". 


\section{A modo de conclusión}

Por lo analizado y expuesto sobre el tema, puede afirmarse que Caldas, en los relativamente pocos años en que se dedicó con intensidad a la botánica (o furor, como él decía), llevó a cabo un trabajo muy vocacional, crítico y sistemático. Logró esbozar un proyecto de flora bien estructurado, con objetivos definidos, sentido práctico y proyección de futuro, que después no pudo concluir por circunstancias ajenas a su voluntad. El reconocimiento y la valoración actual de sus colecciones botánicas, de sus anotaciones descriptivas y etnobotánicas y de su colección de impresiones naturales, como materiales que siguen siendo valiosos para la continuación de la publicación de la Flora de Bogotá (Flora de Mutis), representan hoy, sin duda, un crédito muy tardío. Como ejemplo de una de las especies nuevas publicadas en las últimas décadas, a partir de las colecciones y láminas de la Expedición debidas a Caldas, hacemos referencia a la malvácea Quararibea caldasiana Fern. Alonso (figura 17). Se trata de una especie de zapotillo o molinillo magníficamente iconografiado, árbol recolectado por Caldas probablemente en la vertiente pacífica de Ecuador, donde hoy aún está presente (Fernández Alonso, 2001, pp. 198-200). Por último, cabe anotar que sus obras proyectadas, la Flora Quitoensis y la Phytographya ecuatorialis, que en otras circunstancias pudieron haberse materializado, pasaron a un segundo plano en los tiempos socialmente tumultuosos que hubo de afrontar, no pudiendo ver la luz, tal como Caldas las había pensado. Sin embargo, nunca es tarde para hacer remembranza de estos hechos, pues pensamos que un esfuerzo de esta naturaleza no puede desconocerse ni debe pasar desapercibido para las nuevas generaciones de botánicos en Colombia y Ecuador.

\section{Agradecimientos}

Dejo constancia de mi agradecimiento a los directivos de la Academia Colombia na de Ciencias Exactas, Físicas y Naturales, del Real Jardín Botánico de Madrid del Consejo Superior de Investigaciones Científicas y de la Universidad Distrital Francisco José de Caldas de Bogotá por haber facilitado mi participación en este Congreso Internacional en honor a Francisco José de Caldas. Del mismo modo, agradezco al personal del herbario, archivo y biblioteca del Real Jardín Botánico y de la Academia Colombiana de Ciencias, por el apoyo recibido en la consulta y estudio de la diversa documentación. Por último, mi especial reconocimientoal Dr. Darío Valencia, responsable del Simposio Vida y Obra de Caldas, por las facilidades dadas para la conclusión y entrega de este escrito. 


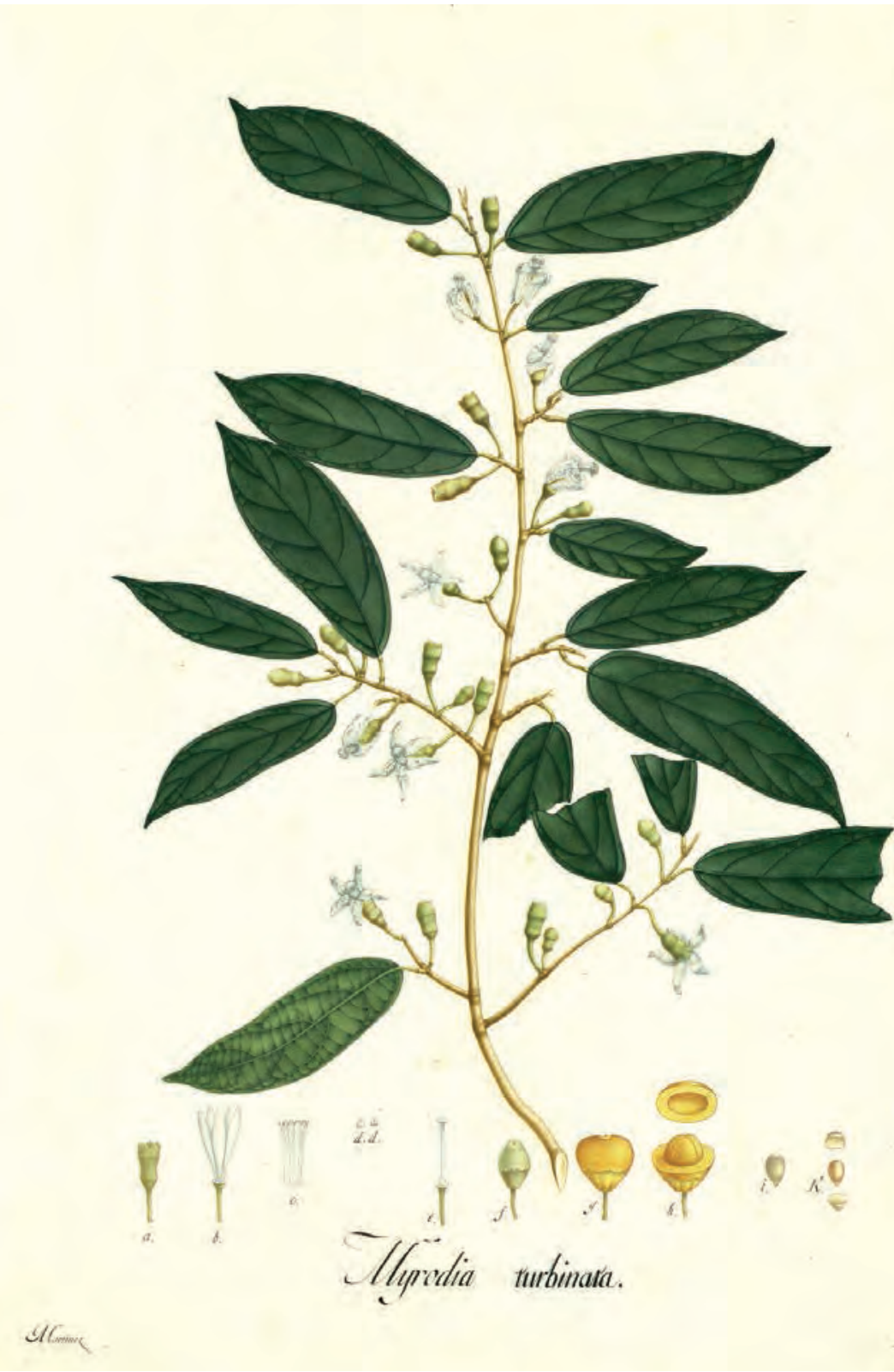

Figura 17. 2uararibea caldasiana Fern. Alonso, Malvaceae. Original del Archivo del Real Jardín Botánico de Madrid. ARJB A02170. 


\section{Referencias}

Caldas, F. J. (1978). Cartas de Caldas. (Bateman, Arias, Ed.). Bogotá: Academia Colombiana de Ciencias Exactas, Físicas y Naturales.

Caldas, F. J. (1809). Ullucus tuberosus. pp. 185. En: Notas al trabajo de Humboldt sobre el mismo asunto. Semanario n. ${ }^{\circ} 16$. Acosta (1894): 339-355, Posada (1912): 356-373.

Díaz Piedrahita, S. (1991). La botánica en Colombia, hechos notables en su desarrollo. Bogotá: Academia Colombiana de Ciencias Exactas, Físicas y Naturales. Colección Enrique Pérez Arbeláez, n. 6.

Díaz Piedrahita, S. (1992). Francisco José de Caldas y la Botánica. Revista de la Academia Colombiana de Ciencias Exactas, Físicas y Naturales, 18(70), 369-382.

Díaz Piedrahita, S. (1997). Nueva aproximación a Francisco José de Caldas. Episodios de su vida y de su actividad cientifica. Bogotá: Academia Colombiana de Ciencias Exactas, Físicas y Naturales. (Vol. CXLıx Biblioteca de Historia Nacional).

Díaz Piedrahita, S. (2001). Asteráceas Tribus Barnadesieae, Mutisieae, Lactuseae y anatomías de las Compuestas. Flora de la Real Expedición Botánica del Nuevo Reino de Granada (Tomo 50). Madrid: Ediciones Cultura Hispánica.

Díaz Piedrahita, S. (2009). Asteráceas Tribu Heliantheae. Flora de la Real Expedición Botánica del Nuevo Reino de Granada (Tomo 48). Madrid: Ediciones Cultura Hispánica.

Fernández Alonso, J. L. (1990). Notas sobre Scutellaria (Labiatae) en Colombia y Ecuador. Anales del Jardín Botánico de Madrid, 47(1), 105-123.

Fernández Alonso, J. L. (1992). Bignoniaceae. Flora de la Real Expedición Botánica del Nuevo Reino de Granada (Tomo 41), pp. 1-50, lám. 1-27. Madrid: Ediciones Cultura Hispánica.

Fernández Alonso, J. L. (1995). Estudios en Labiatae de Colombia I. Novedades en los géneros Salvia e Hyptis. Revista de la Academia Colombiana de Ciencias Exactas, Físicas y Naturales, 19(74), 469-480.

Fernández Alonso, J. L. (1996). Labiatae. Flora de la Real Expedición Botánica del Nuevo Reino de Granada. (Tomo 37). Manuscrito inédito.

Fernández Alonso, J. L. (2001). Bombacaceae neotropicae novae vel minus cognitae I. Novedades en los géneros Matisia, Quararibea y Spirotheca. 
Revista de la Academia Colombiana de Ciencias Exactas, Físicas y Naturales, 25(95), 183-206.

Fernández Alonso, J. L. y Rivera, O. (2006). Labiatae. Libro Rojo de Plantas de Colombia. (Galeano y García, Ed.), pp. 385-582. Serie Libros Rojos de especies amenazadas de Colombia, Vol. 3. Bogotá: Instituto Alexander von Humboldt, Instituto de Ciencias Naturales de la Universidad Nacional de Colombia, Ministerio de Ambiente, Vivienda y Desarrollo Territorial. Linné, C. von (1792). Philosophia Botanica. Madrid.

Neill, D. A. (2012). ¿Cuántas especies nativas de plantas vasculares hay en Ecuador? Revista Amazónica Ciencia y Tecnología, 1(1), 70-83.

San Pío Aladrén, M. P. de (Coord.) (1995). Catálogo del Fondo Documental José Celestino Mutis del Real Jardin Botánico. Bogotá: Instituto. 
Bicentenario. Francisco José de Caldas, 1768-1816 / Comité editorial: Yolima Álvarez Polo, Carlos Alberto Díez Fonnegra, Asdrúbal Moreno Mosquera, Iván Felipe Suárez Lozano; con el apoyo de: Luis Carlos Arboleda, Darío Valencia Restrepo.

- Bogotá: Editorial Universidad del Rosario, 2019.

$x x, 478$ páginas.

Incluye referencias bibliograficas.

Caldas, Francisco José de, 1768-1816 / Real Expedición Botánica del Nuevo Reino de Granada, 1783-1816 / Científicos colombianos / Botánicos - Colombianos / Fitoterapia / I. Forero, Enrique / II. Lancheros, Daniel / III. Gómez Gutiérrez, Alberto / IV. Amaya, José Antonio / V. Suárez Lozano, Iván Felipe / VI. Freites, Yajaira / VII. Eychenne, Bertrand / VIII. Rey Rey, Juan Manuel / IX. Reguera Vảzquez, Celina / X. Iglesias Blanco, Rita / XI. Ballbé Mallol, Xavier / XII. Valencia Restrepo, Dario / XIII. Pabón Caicedo, José Daniel / XIV. Ardila, Rubén / XV. Portilla, José Gregorio / XVI. Andrade C., M. Gonzalo / XVII. Henao, Efraín / XVIII. Pohl Valero, Stefan / XIX. Fernández Alonso, José Luis / XX. Appel, Wilton John / XXI. Ochoa, Andrés / XXII. Nieto Olarte, Mauricio / XXIII. Gómez Carder, Gabriel Jaime / XXIV. Cogollo Pacheco, Álvaro / XXV. Ramírez Martínez, Sandra Milena / XXVI. Moreno Mosquera, Asdrúbal / XXVII. Álvarez Polo, Yolima / XXIV. Caldas Varona, Diego / XIX. Suárez Lozano, Iván Felipe / XXX. Reina Rodriguez, Carlos Arturo / XXXI. Appel, John William / XXII. Garcia Guillén, Esther / XXXIII. Universidad del Rosario. / XXXIV. Título / XXXV. Serie.

925. SCDD 20

\section{Caralogación en la fuente - Universidad del Rosario. CRAI}

(c) Editorial Universidad del Rosario

(c) Universidad del Rosario

(c) Varios autores

(c) Enrique Forero, por la Presentación

(c) Luis Carlos Arboleda, por la Introducción

Editorial Universidad del Rosario

Carrera 7 No. 12B-41, of. 501 - Tel: 2970200 Ext. 3112 editorial.urosario.edu.co
Primera edición: Bogotá D. C., marzo de 2019

ISBN: 978-958-784-191-6 (impreso)

ISBN: 978-958-784-192-3 (ePub)

ISBN: 978-958-784-193-0 (pdf)

DOI: doi.org/10.12804/th9789587841923

Coordinación editorial: Editorial Universidad del Rosario

Corrección de estilo: Ludwing Cepeda Aparicio

Diseño de cubierta y diagramación:

Precolombi EU-David Reyes

Impresión: Xpress. Estudio Gráfico y Digital S.A.S.

Impreso y hecho en Colombia

Printed and made in Colombia

Los conceptos y opiniones de esta obra son responsabilidad de sus autores y no comprometen a la Universidad ni sus políticas institucionales.

El contenido de este libro fue sometido al proceso de evaluación de pares para garantizar los altos estándares académicos. Para conocer las políticas completas visitar: editorial.urosario.edu.co

Todos los derechos reservados. Esta obra no puede ser reproducida sin el permiso previo escrito de la Editorial Universidad del Rosario. 